\title{
Status and distribution of ungulates in Xinjiang, China
}

\author{
XingYi GAO ${ }^{1}$, WenXuan XU ${ }^{1,2}$, WeiKang YANG ${ }^{1 *}$, David A BLANK ${ }^{1,3}$, JianFang QIAO ${ }^{1}$, KeFen XU ${ }^{1}$ \\ ${ }^{1}$ Key Laboratory of Biogeography and Bioresource in Arid Land, Xinjiang Institute of Ecology and Geography, Chinese Acad- \\ emy of Sciences, Urumqi 830011, China; \\ ${ }^{2}$ Graduate University of Chinese Academy of Sciences, Beijing 100049, China; \\ ${ }^{3}$ Institute of Zoology, Kazakhstan Academy of Sciences, Almaty 050010, Kazakhstan
}

\begin{abstract}
Based on a long-term field investigation and other research results, we reviewed the status and distribution of ungulates in Xinjiang, China. The ungulates in Xinjiang included 19 ungulate species (30 subspecies) from 6 families and 2 orders. Among them, 3 species (2 subspecies) relate to Equidae (Perrisodactyla), and 16 species (28 subspecies) are from 5 families of Artiodactyla. In this paper, we analyzed the conservation status of most rare and important 13 ungulate species. Firstly, we proposed the protection of genetic diversity of Camelus ferus and the distribution areas of Moschus sifanicus, Procapra przewalskii and Saiga tatarica in Xinjiang. We found that Moschus sifanicus but not Procapra przewalskii distributed in Xinjiang. It was not clear whether the remnant populations of Saiga tatarica existed in Xinjiang and China-Kazakhstan border or not. We discussed that the protection level and rational use of Capra sibirica and enhancing protection level and enlarging monitoring and research projects for Pantholops hodgsoni and Gazella subgutturosa. And we would like to suggest Forestry Department to develop the captive breeding of Tibetan antelope for rational use. In addition, the captive breeding of Cervus elaphus in Xinjiang was reviewed. Local government should lessen strong control to Cervus elaphus because of many breeding centers' establishment.
\end{abstract}

Keywords: Xinjiang of China; ungulate; species and distribution; status

\section{Introduction}

Xinjiang Uygur Autonomous Region is situated in northwestern China and covers an area of $1.66 \times 10^{6}$ $\mathrm{km}^{2}$ that is equal to one sixth of the whole territory of China. The landscape of Xinjiang is very various and characterized by alternation of mountains and basins. Altay Mountains are located in the north and Kunlun Mountains in the south. Tianshan Mountains in the middle of Xinjiang dividing this region into two parts: the Tarim Basin in the southern part and the Junggar Basin in the northern part (Fig. 1). Because Xinjiang is situated in the center of the Eurasian continent and far away from oceans and surrounded by high mountains, the conditions form the typical extremely dry continental climate. As a consequence, Xinjiang has great difference of climate between its southern and northern parts. The mean temperature of January in northern part is $-17^{\circ} \mathrm{C}$ and $-10^{\circ} \mathrm{C}$ in southern part. In July, the mean temperature is up to $25^{\circ} \mathrm{C}$ in the north and $27^{\circ} \mathrm{C}$ in the south. The precipitation distribution is ex- tremely uneven. In general, the precipitation in the north is more than that in the south and that in the west more than that in the east, that in mountains more than that in basins of Xinjiang. The average annul precipitation in the Junggar Basin is 150-200 mm (northern Xinjiang), below $50 \mathrm{~mm}$ in Tarim Basin (southern Xinjiang), and only $10-30 \mathrm{~mm}$ in the Turpan-Hami Basin (eastern Xinjiang), while the average annual precipitation in Altai and Tianshan Mountains are 500-600 $\mathrm{mm}$ and 900-1,000 mm, respectively.

Peculiar geographic locations, various landscapes, and native environments of Xinjiang provide diverse habitats for many wild animals. Here, mammals are outstanding by its biodiversity, numerous species/subspecies, and wide distribution range and population density. There are 5 species from 2 families of Perrisodactyla in China, 3 species from them belong-

Received 2010-08-03, accepted 2010-11-10

doi: 10.3724/SP.J.1227.2011.00049

* Corresponding author: WeiKang YANG (E-mail: yangwk@ms.xjb.ac.cn) 


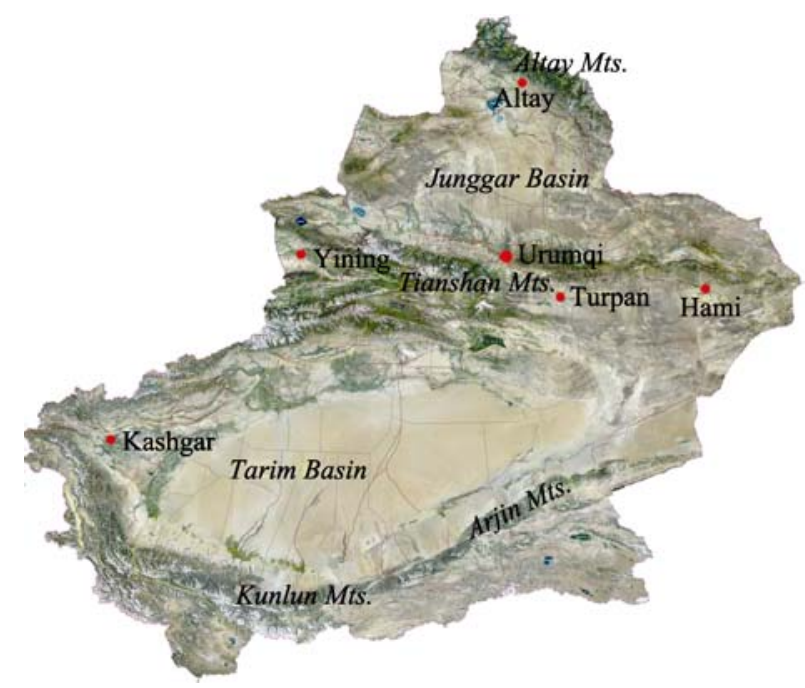

Fig. 1 Map of Xinjiang Uygur Autonomous Region

ing to Equidae which lives in Xinjiang. There are 48 species of Artiodactyla from 6 families in China, and 16 species from 5 families which inhabits in Xinjiang (Gao, 2003; Wang, 2003). Some measures for wildlife protection were done in Xinjiang, as a result, the number of ungulate populations started to increase. It causes new tasks for protection and management. In this paper we reported the status and distribution of ungulates in Xinjiang.

\section{Species and geographic distribution}

The ungulates in Xinjiang have 19 species (30 subspecies) belonging to 6 families and 2 orders. Among them, 3 species ( 2 subspecies) belong to Equidae (Perrisodactyla), and 16 species (28 subspecies) relate to 5 families of Artiodactyla (Gao et al., 2001). Ten species are spread in Kunlun Mountains and Arjin Mountains and Pamir Plateau, 7 species in Altay Mountains, 7 species in Gobi desert, 6 species in Tianshan Mountains and western mountains of Junggar Basin, 5 in Junggar Basin and 4 in Tarim Basin. Generally, 15 species of ungulates $(79 \%)$ are distributed in the mountains and plateaus of Xinjiang. According to the habitat types, 11 species are distributed in grassland and alpine grassland, 11 species in deserts and mountain deserts, 6 species in forest, 4 species in rocky area of mountains and highland bushes, while only 1 species occurred in wetland, farmland and settlement area. Totally, 14 species of ungulates $(74 \%)$ in Xinjiang are distributed in grassland and desert (Table 1).

\section{Status and conservation of ungulates in Xinjiang}

Some species of ungulates have been extinct in field, and others are endangered and have not enough data recording them in the list of species in Xinjiang. Most species have high economic value. This information may be used for protection and restoring natural habitat of these animals.

\subsection{Wild horse, Equus przewalskii}

Wild horse or Przewalski's horse (Equus przewalskii) is protected as grade I in the list of the state protected animals, and China Red Data Book, Appendix I in CITES (Convention on International Trade in Endangered Species of Wild Fauna and Flora) and classified as an extinct species of field (EW) in IUCN (International Union for Conservation of Natural Resources) and was ever spread in Junggar Basin, northern Xinjiang and China-Mongolia border in northern Gansu Province. The wild horses only have breeding population in Xinjiang now and were released in Kalamaili Nature Reserve in 2001. Formerly, wild horses were spread overall vast steppe zone of Asia. Since the $19^{\text {th }}$ century, the natural habitat of wild horses began to decrease, their number reduced sharply during the $20^{\text {th }}$ century till their extinction from field in 1969. The main causes of the extinction include the climatic change, increasing number of livestock, overgrazing, mineral resources exploration and hunting, especially severe winters in 1948-1956 (Bannikov, 1980). Sokolov (1959) reported that wild horses were spread along the China-Mongolia border on an area of $300,000 \mathrm{~km}^{2}$ from Junggar Basin via Mazongshan in Gansu Province to southwestern Mongolia $\left(41^{\circ} 37^{\prime}-47^{\circ} 11^{\prime} \mathrm{N}, 86^{\circ} 10^{\prime}-100^{\circ} 15^{\prime} \mathrm{E}\right)$ during the late $19^{\text {th }}$ century. According to Allen (1938), wild horses were distributed in north slope of Altay Mountains on an area of $75,000 \mathrm{~km}^{2}\left(46^{\circ}-49^{\circ} 35^{\prime} \mathrm{N}, 87^{\circ} 40^{\prime}-94^{\circ} \mathrm{E}\right)$. Bannikov (1958) reported that wild horse lived in eastern Junggar Basin, China-Mongolia border area in $1950 \mathrm{~s}$, with a smaller area of $20,000 \mathrm{~km}^{2}$ $\left(44^{\circ} 20^{\prime}-45^{\circ} 23^{\prime} \mathrm{N}, 91^{\circ} 00^{\prime}-94^{\circ} 30^{\prime} \mathrm{E}\right)$. Gao (1985) believed that some remnant individuals of wild horses spread in the border area of China-Mongolia, in the eastern Baytik Mountain in an area about $10,000 \mathrm{~km}^{2}$ $\left(44^{\circ} 44^{\prime}-45^{\circ} 13^{\prime} \mathrm{N}, 91^{\circ} 46^{\prime}-94^{\circ} 50^{\prime} \mathrm{E}\right)$. 
Bannikov (1980) reported that Przewalski's horses were commonly seen in field during 1940s, while people can only see singles or small groups occasionally in 1960s. The last wild horses were recorded in 1969. Since 1980s, we carried out several investigations for searching Przewalski's horses, but no one was found in field. So, we believed that they have been extinct from the fauna of China (Gao, 1985, 2002). Przewalski's horses, staying in captivity long time and having close breeding, lost their genetic diversity. As a result, the captive population of wild horses had low vitality, low reproduction and many diseases. All these factors were main threat for Przewalski's horses in captivity. In order to save wild horses and keep their genetic diversity, it is necessary to reintroduce them in the regions of the former natural habitat, and northern Xinjiang is one of the regions; therefore reintroducing these horses into the wild is obligatory task for China. The State Forestry Administration of China implemented a long term project for Przewalski's horses backing to nature. That's why 11 wild horses from German and England zoos were transferred to China in 1985 (Table 2). During next 20 years (1985-2005), totally 25 wild horses were brought to China. Meanwhile, the Przewalski's horse breeding center was established in Jimsar county, Xinjiang in 1986. The breeding center was responsible for keeping, breeding, reintroducing and re-establishing wild population of these horses in China. Reproduction of wild horses in captivity has been successfully implemented, born 335 horses and 231 from them survived till 2008 (Table 3). The project started in August 2001 decided that such herd would be enough for reintroduction. In general, reintroduced horses had adapted to food, water and natural environment conditions and they enlarged their home range and formed stable herd in nature conditions. The breeding rate was quite high during 2003-2008. Totally, 47 foals were born in the wild conditions and 27 from them survived. That is, the project for reintroduction of Przewalski's horses had got preliminary success in China, and 56 reintroduced horses have formed 6 groups in Junggar Basin of Xinjiang.

\subsection{Mongolian Wild Ass, Equus hemionus hemionus}

Asiatic wild ass (Equus hemionus) consistes of 5 subspecies: Kazakh (or Kulan) E. h. kulan, Persian (or Onager) E. h. onager, Indian (or Khur) E. h. khur,
Table 2 Przewalski's horses were transferred from overseas' zoos into wild horse breeding center in Xinjiang

\begin{tabular}{cccc}
\hline \multirow{2}{*}{ Date } & \multirow{2}{*}{ Country } & \multicolumn{2}{c}{ Number } \\
\cline { 3 - 4 } & Male & Female \\
\hline July, 1985 & The former East Germany & 2 & 3 \\
Aug., 1985 & Britain & 2 & 4 \\
June, 1988 & The former West Germany & 2 & 3 \\
Dec., 1991 & USA & 2 & \\
Sep., 2005 & Germany & 6 & \\
Total & & 14 & 10 \\
\hline
\end{tabular}

The data were provided by Xinjiang wild horse breeding center

Table 3 Przewalski's horses reintroduced into the Kalamaili Nature Reserve, Xinjiang, China

\begin{tabular}{crccccc}
\hline \multirow{2}{*}{ Date } & \multicolumn{3}{c}{ Number } & \multicolumn{4}{c}{ Age structure } \\
\cline { 2 - 7 } & Total & Male & Female & Adult & Sub-adult & Foal \\
\hline $2001-08-28$ & 27 & 11 & 16 & 11 & 10 & 6 \\
$2002-02-09$ & 2 & 2 & & 2 & & \\
$2002-05-24$ & 5 & 5 & & 4 & 1 & \\
$2004-07-30$ & 10 & 2 & 8 & 7 & 2 & 1 \\
$2007-06-03$ & 6 & 6 & & 6 & & \\
$2008-07-20$ & 6 & & 6 & 6 & & \\
Total & 56 & 26 & 30 & 36 & 13 & 7 \\
\hline
\end{tabular}

The data were provided by Xinjiang wild horse breeding center

Mongolian (or Khulan) E. h. hemiones and extincted Syrian (E. h. hemippus). Only one of them, the Mongolian subspecies of wild ass or khulan (Equus hemionus hemionus) inhabits in Xinjiang. This species have been listed as a rare in China Red Data Book of endangered animal, classified as a Category I protected species. E. hemionus was also included in the Appendix I of CITES and listed as endangered by IUCN. During mid $17^{\text {th }}$ to $19^{\text {th }}$ centuries, natural habitat of khulan covered the most part of Mongolia, some areas in Siberia and northeastern China. In Xinjiang, wild asses were distributed in the northern and eastern parts of Junggar Basin, in the China-Mongolia border area. Besides, they lived in western Inner Mongolia and northwestern Gansu Province. At present, wild ass can be seen in Junggar Basin eastward from Mori, Barkol and Yiwu, and distributed mostly in Kalamaili Nature Reserve. Early reports informed that population of wild asses in China was not more than 2,000 individuals (Gao and $\mathrm{Gu}, 1989$ ). Following information affirmed that distribution area of Mongolian wild asses in Kalamaili Nature Reserve was 2,300 $\mathrm{km}^{2}$, and 
the mean density was $1.2 \pm 0.49$ individuals $/ \mathrm{km}^{2}$, and the size of population ranged 1,633-3,887 individuals (Xu et al., 1997). Since 1980s, the population number of wild ass in China has increased almost twice. The population number in the Kalamaili Nature Reserve is 3,300 - 5,300 individuals at present (Chu et al., 2009).

\subsection{Kiang, Equus kiang}

Kiang was listed as Least Concern in IUCN (Shah, 2008), classified as Category I state protected species and Vulnerable (VU) in China Red Data Book. E. kiang was included into Appendix II of CITES. There are 3 subspecies of kiangs over the world and 2 subspecieslive in China. Kiangs are distributed in the Qinghai-Tibet Plateau and adjacent areas. Equus kiang spreads in Tibet and Xinjiang, and E. kiang holdereri lives in Gansu, Qinghai and Sichuan Provinces. In Xinjiang, kiang occurs in Kunlun Mts., Karakorum Mts. and Pamir Plateau.

Kiangs live in the alpine cold steppe and cold desert of 3,600-5,400 $\mathrm{m}$ above sea level. They prefer plains and hills, broad and open basins, valleys around lakes. E. kiang feeds mostly graminoids and sedges such as Stipa, Poa and Carex.

Density of E. kiang in the eastern Kunlun Mountains was 0.917 individiuls $/ \mathrm{km}^{2}$ with population number of 41,262 (Gu, 1987). The total number of Kiang in China was estimated with 200,000 individuals (Wang, 1998) and 60,000-70,000 individuals (Schaller, 1998).

\subsection{Wild Bactrian camel, Camelus ferus}

Wild Bactrian camel was listed as Critically Endangered by IUCN (Hare, 2008) and as Category I state protected species and VU in the China Red Data Book. Bactrian camel lives in extremely arid deserts of Mongolia and China (Xinjiang Uygur Autonomous Region and Gansu Province). The DNA results for the wild bactrian camels showed two or three distinct genetic differences compared with the domestic bactrian camel ( $3 \%$ basic difference). IUCN considers the wild species of the bactrian camel as a Camels ferus, while the domestic form is considered as a Camelus bactrianus (Gentry et al., 2004). They spread in Tarim Basin, Arjin Mountains and eastern Xinjiang.

Bannikov (1958) reported that wild camel distributed mostly in Altay Gobi across the China-Mongolia border, and the Kuluk desert of southern Turpan.
Sokolov (1959) reported that the distribution area of wild camel was formed by three small isolated areas: (1) Eastern Xinjiang and border region with Gansu and Qinghai provinces; (2) Altay Gobi bordering with Mongolia (northeastern Xinjiang); (3) Downstream of Keliya River in the internal region of Taklamakan desert. Gu et al. (1991) reported four small isolated areas of bactrian camel inhabitation in China: Gashun Gobi and Lop Nur, Arjin Mountains, Taklamakan desert and Altai Gobi.

This species spread in arid deserts and small basins of mountain regions with elevation of $780-3,000 \mathrm{~m}$ above sea level. They may endure extremely hot and cold weather, feed by different and numerous desert plants. The estimated number of Chinese population was 1,000 individuals in 1980s (Gao, 1985) or over 1,000 (Gu et al. 1991) in 1990s, but later their number decreased to 730-880 individuals (Wang, 1998; Yuan et al., 1999). It is Critically Endangered species in China.

\subsection{Alpine musk deer, Moschus chrysogaster}

Alpine musk deer was classified as Category II state protected species, listed as Endangered in IUCN Red Data List (Wang and Harris, 2008) and China Red Data Book, Appendix II in CITES. This species occurs in China, Nepal, Bhutan, India, Pakistan and Afghanistan. In China, it was found in Gansu, southern Ningxia, Qinghai, western Sichuan, southern Tibet, and northern Yunnan. In Gansu, the distribution area is adjacent to rocky mountain massifs in eastern Xinjiang (Wang, 1991; Wang, 2003). There was not recorded in Xinjiang. In 1993, authors found one individual in rocky massifs of eastern Tianshan Mountains. This species was recorded firstly in Xinjiang though it is quite rare in this region (Gao, 2003).

\subsection{Red deer, Cervus elaphus}

Red deer was classified as Category II protected species in China, and Least Concern in IUCN Red Data List (Lovari et al., 2008), endangered (EN) in Chinese Red Data Book. This species is distributed widely from Central and North Asia and Central Europe to North Africa and North America. In China, it was found in northwestern areas including Xinjiang, Gansu, Qinghai, Sichuan, Ningxia, Helan Mountains and eastern Tibet Plateau. Red deer (Cervus elaphus) have 19 subspecies (or 22 subspecies according to different 
authors). Among of them, 8 subspecies occured in China (Cervus elaphus xanthopygus in northeast China, C.elaphus songaricuss in Tianshan Mountains, C. elaphus yarkandensis in Tarim Basin, C. elaphus kansuensis in Gansu, C. elaphus sibiricus in Altay Mounatins, C.elaphus wallichi in Tibet, C. elaphus macnerlli in Sichuan and C. elaphus alashanmicus in Inner Mongolia) and 3 subspecies in Xinjiang (C. e. sibiricus distributes in Altay Mountains, C. e. songaricus spreads in Tianshan Mountains and western Junggar Basin, and C. e. yarkandensis in Tarim Ba$\sin )$.

In China, red deer is an important source of biological active material for traditional medicine. Captive breeding of this species has quite long history in Xinjiang. The first captive breeding center for red deer was established in Gongliu County, Xinjiang in 1956. The second breeding center was built in Yining County in 1958. And after this, many red deer breeding centers were set up in Hami, Yanqi, Shaya and Aksu of Xinjiang. The number of captive red deer in Xinjiang was about 4,500 individuals in 1973, 10,400 individuals in 1986, and over 20,000 individuals in mid-1990s. Red deer became a great income of economy in some districts. At present, there are more than 2,000 captive red deer breeding centers with nearly 50,000 individuals in Xinjiang.

This species inhabits in forests, grasslands, and meadow grasslands. C. e. yarkandensis in Tarim Basin lives in Populus diversfolia forest, reed meadow and shrubs. They stay in valleys or south slopes of mountain in winter and north slope in summer. Their diet includes many plants; they feed green leaves and shrub branches and grasses in summer, fruits in autumn and winter. They also eat dry grasses and leaves, small branches and cortices sometimes.

In 1990s, there are about 4,000 individuals in the northern slope of Tianshan Mountains (Gao et al., 1997). Yu et al. (1996) reported that the population number was about 8,447 deer in northern slope of western Tianshan Mountains around Ili River. In the consequence of government to strength the protection and management measures in recent years, the number of red deer population increased obviously and they became common species in forest.

\subsection{Wild yak, Bos mutus}

Wild yak was classified as a Category I state protected species, endangered (EN) in the China Red Data Book and IUCN red list (Harris and Leslie, 2008), Appendix I in CITES. Wild yak was spread in Qinghai-Tibet Plateau and adjacent regions including Tibet, Sichuan, Qinghai, Xinjiang and Gansu. At present, they distributed mostly in northern Qinghai-Tibet Plateau, and in Xinjiang, where they can be only seen in Kunlun and Karakorum Mountains. This is an endemic species.

The wild yaks inhabit in open areas of alpine cold grasslands and meadow grasslands, alpine cold deserts. They usually live in small valleys, banks of lakes and mountain slopes on elevations of 4,000-5,000 m above sea level. Usually, the group size of wild yak is over 10 individuals, sometimes up to 200 individuals. They have wide range of food plants, but they prefer Poaceae species.

The number of wild yak population in the Kumkule Basin, eastern Kunlun Mountains, was about 3,031 individuals (Gu, 1987). Total number of wild yak in Qinghai-Tibet Plateau was about 60,000-70,000 individuals. Among them, 30,000-40,000 individuals of wild yak occurred in Kunlun-Karakorum Mountains (Feng, 1992).

\subsection{Goitred gazelle, Gazella subgutturosa}

Goitred gazelle was classified as Category II state protected species, listed as VU in China Red Data Book and IUCN red list. It was distinguished six subspecies all over the world: G. s. subgutturosa distributed in Iran, Afghanistan and Middle Asia; G. s. yarkandensis, G. s. sairensis and G. s. reginae in China; $G$. s. hillieriana in Mongolia and China; G. s. marica in Saudi Arabia, almost extinct in the wild now and only captive population exists (Li et al., 1989; Wang, 1991; Zheng et al., 1994; Wang, 1998). Four subspecies can be found in Xinjiang: G. s. sairensis in Junggar Basin, Tacheng Basin and its adjacent areas; G. s. hillieriana in eastern Xinjiang and its neighboring areas; $G$. $s$. yarkandensis in Tarim Basin and Turpan; G. s. reginae in Kunlun and Arjin Mountains.

Goitred gazelle is a typical drought-tolerant species, which inhabits in plains, rolling hills, deserts and semi-deserts. Gazelles have seasonal migrations. They form herds from 2-6 individuals, as a rule. Their group size is big during winter and reaches $20-30$ in- 
dividuals, and sometimes over 100 individuals. In Kunlun Mountains, gazelles may occur at the elevation of 3,500 $\mathrm{m}$ above sea level. Goitred gazelles have very good adaption to the arid environment. They may endure extremely drought and cold weather. They have wide ranges of food categories and eat many desert plants, such as Allium, Salsola, Artermisia, Haloxylon, Anabasis and some Graminoids.

In early 1990s, the density of G. s. sairensis in Junggar Basin was $0.71 \pm 0.17$ individuals $/ \mathrm{km}^{2}$, and the density of G. s. yarkandensis was $0.57 \pm 0.26$ individuals $/ \mathrm{km}^{2}$ (Gao et al., 1996); in mid 1990s, the densityof G. s. sairensis in Changji was $0.80 \pm 0.24$ individuals $/ \mathrm{km}^{2}$, with the population number of 13,014-24,336 (Gao et al., 1997), and the density in Kalamaili Nature Reserve was $0.83 \pm 0.36$ individuals $/ \mathrm{km}^{2}$, with the population number of 7,426-18,802 individuals (Xu et al., 1997). According to our survey, the density of Goitred gazelle in Hami Basin at present may be classified for three levels: $3.33 \pm 0.24$ individuals $/ \mathrm{km}^{2}$, $0.95 \pm 0.055$ individuals $/ \mathrm{km}^{2}$ and $0.056 \pm 0.042$ individuals $/ \mathrm{km}^{2}$, and the total number of gazelles population in Hami Basin is $37,108 \pm 4,420$ individuals (Gao and Yao, 2006).

\subsection{Przewalski's gazelle, Procapra przewalskii}

Przewalski's gazelle was classified as Category I state protected species, listed as endangered (EN) in China Red Data Book and IUCN red list. The distribution area of Przewalski's gazelle is confined the region around Qinghai Lake. This species lives on steppe plateau and open valleys (Jiang and Wang, 2001). Przewalski's gazelle was classified as primary protected species in "Antelopes: Global Survey and Regional Action Plans" (Jiang et al., 2004). Zheng (1994) recorded these gazelles distributed in Arjin Mountains, but nobody could find them after many years of investigations. Besides, the environmental conditions of Arjin Mountains are not suitable for Przewalski's gazelle. Apparently, this species did not distribute in Arjin Mountains. Jiang et al. (2004) reported that the population number of Przewalski's gazelle is only 285-338 individuals. It is critically endangered species in China.

\subsection{Tibetan antelope, Pantholops hodgsonii}

Tibetan antelope was classified as Category I state protected species, endangered (EN) in the China Red
Data Book and IUCN red list, Appendix I in CITES. It ranged overall the Qinghai-Tibet Plateau and its adjacent areas. In China, Tibetan antelope can be found in Tibet, Qinghai, Sichuan, Gansu and Xinjiang. In Xinjiang, it can only be seen in Kunlun and Karakorum Mountains.

Tibetan gazelles live in highland plains, undulating hills and monotone valley on elevations of 4,000-5,000 $\mathrm{m}$ above sea level. They prefer alpine cold meadows, alpine cold steppes and deserts. Tibetan antelopes graze grasses and browse tender branches and green leaves of shrubs.

Fourteen surveys were done for Tibetan antelopes during the period of 1976-1990, and 17,000-18,000 individuals were found totally. It was estimated that about 90,000 individuals to live in Karakorum-Kunlun Mountains and more than 100,000 antelopes inhabited on the whole Qinghai-Tibet Plateau (Feng, 1992). Gu (1987) reported that the mean density of Tibetan antelopes in Kumkule Basin, easterh Kunlun Mountains was 1.375 individuals $/ \mathrm{km}^{2}$. Schaller (1998) supposed that the total number of Tibet antelopes is not more than 50,000 individuals in Tibet, and about 25,000 in Qinghai and Xinjiang. The population number of Tibetan antelopes has grown up obviously in recent years, because effective conservation measures and their natural habitat have been done.

\subsection{Saiga, Saiga tatarica}

Saiga was classified as Category I state protected species, listed as endangered (EN) in IUCN red list, Appendix I in CITES, Extinct (ET) in the China Red Data Book. This species was spread in Mongolia, Kazakhstan, Turkmenistan and Russia. Formerly, this species was distributed in northeastern Junggar and Tacheng Basins and the area nearby Junggar Gate before extinction from fauna of China during 1960s. Some remnant populations of Saiga tatarica may still be found in the border between China and Kazakhstan.

Saiga is a nomadic herding species that generally inhabits in open dry steppe and semi-arid deserts of Central Asia. Saiga always forms small groups, however, they concentrated in large herds during migration time in spring and autumn. During spring (May) saigas migrate to the north, from winter pastures to steppe and summer pastures for giving births, and in autumn they migrate far to the south. They eat 
Graminoids, Artermisia and some salty shrub species.

It was defined two subspecies of saiga: Saiga tatarica tatarica and Saiga tatarica mongolica. First, the nominative subspecies is most numerous and it spreads overall Kazakhstan, Turkmenistan and Russia. At the end of World War II, the number of this subspecies was only 90,000 individuals, but later, it rose significantly and reached 1,300,000 individuals in 1960, and it sharply declined again since 1980s (Wang, 1998). Other subspecies, Saiga tatarica mongolica is an endemic of western Mongolia and north-eastern of Xinjiang. During the period of 1940s-1950s, saigas lived around lakes in western Mongolia, where population number was 1,020 individuals in 2003 and 750 antelopes in January of 2004 (Mallon, 2008).

\subsection{Argali, Ovis ammon}

Argali was classified as Category II state protected species, listed as Near Threatened in IUCN red list and endangered (EN) in the China Red Data Book, Appendix I (O. a. hodgsoni) and II (other subspecies) in CITES. Argali is widely distributed in mountains of Middle Asia and was found in northeastern Afghanistan, China (Gansu, Inner Mongolia, Qinghai, possibly western Sichuan, Tibet, and Xinjiang), northern India, eastern Kazakhstan and Kyrgyzstan, Mongolia, northern Nepal (near the Chinese border), northern Pakistan, Russia (Altay Mountains), eastern Uzbekistan and Tajikistan (Fedosenko and Blank 2005). It was described 12 subspecies of argali. Ten among them inhabit in China and 8 of them inhabit in Xinjiang: nominative subspecies (O. a. ammon) lives in Altay Mountains; $O$. a. sairensis in mountains of western Junggar Basin; $O$. a. darwini on the Chinese-Mongolian border; O. a. littledalei in northern Tianshan; O. a. karelini in southern Tian Shan (northern from Akqi); O. a. adamelzi in Kuluk Mountains (northeastin Lop Nur Lake); O. a. polii spread in Pamir, western Kunlun Mountains and southern Tianshan (southin Akqi); and O. a. dalailamae in eastern Kunlun and Arjin Mountans.

Argali prefers semi-opened rocky area of mountains, their habitats include bald rocky area of high mountain, alpine grassland, shrubs and rocky desert hills, with elevation from 1,000 to 5,500 $\mathrm{m}$ above sea level. They may cross steep slopes easily, and get over several mountain ridges. Usually, argali forms small groups (several individuals to dozens) in non-breeding sea- sons and large ones in winter. Their food composition includes graminoids, Allium, some forbs and green twigs and leaves of shrubs.

According to the data provided by Endangered Species Program, US Fish and Wildlife Service (November, 1989) in the conference for Argali, the total number of argali sheep estimated all over the world was 160,000 individuals, and 100,000 argali live in China. Zhao (1991) supposed that the number of argali population in China was about 80,000 individuals, while Gu et al. (1991) affirmed that only in Xinjiang, it was possible to be found about 50,000-80,000 individuals. Gao and Yao (1997) reported that the mean density of argali in eastern Tian Shan Mountains (Mori County) was $0.82 \pm 0.25$ individuals $/ \mathrm{km}^{2}$. Recent data from some local hunting teams showed that the argali density in Tuolimayile Mountains was $1.07 \pm 0.38$ individuals $/ \mathrm{km}^{2}$ and Wuerkxiaer Mountains was $1.78 \pm 0.25$ individuals $/ \mathrm{km}^{2}$ (western Junggar Basin); $0.90 \pm 0.48$ individuals $/ \mathrm{km}^{2}$ in south slope of Bogda Mountains (eastern Tianshan); 0.72 to 1.87 individuals $/ \mathrm{km}^{2}$ in Gurengou and Bayinguoleng (Central Tianshan); $\quad 1.92 \pm 0.68$ individuals $/ \mathrm{km}^{2}$ in Kuluk Mountains (southern Turpan); $1.89 \pm 0.17$ individu$\mathrm{als} / \mathrm{km}^{2}$ in Keksen of Burqin County (Altay Mountains). These data demonstrated that populations' number grows up obviously at present, and large groups over 100 individuals can be seen in some areas.

\subsection{Blue sheep, Pseudois nayaur}

Blue Sheep or Bharal was listed as Least Concern in IUCN 2003 (Harris, 2008), VU in Chinese Red Data book and protected as Category I state protected animals. This species was found in Sikkim, Bhutan, Nepal, northern India, northern Myanmar, northern Pakistan and China (Gansu, Ningxia-Inner Mongolia border, Qinghai, Sichuan, Tibet, southeastern Xinjiang, and northern Yunnan-Rabinowitz, 1996). Some authors recognized two subspecies, $P$. n. nayaur and P. $n$. szechuanensis. In Xinjiang, P. n. szechuanensis is distributed in Arjin and Kunlun Mts., and Pamir Plateau.

Blue sheep inhabits in open grassy slopes of high mountains on the elevation of $2,500-5,500 \mathrm{~m}$ above sea level. They usually stay near cliffs or similar landscapes with escape cover. They feed on grass and alpine herbs and lichens and live in small to rather large herds, alternately resting and feeding on steep 
grassy slopes of alpine meadows.

Zheng (1989) reported that the density of blue sheep was 3.3 individuals $/ \mathrm{km}^{2}$ in Yanchiwan Nature Reserve, Gansu province. According to field investigation in 1972, there were about 92,000 individuals in eastern Qinghai (Wang, 1998). Gu (1990) estimated that there were about 10,000 individuals in the Arjin Mts. Nature Reserve with a density of 4.5 individuals $/ \mathrm{km}^{2}$. Schaller et al. (1987) reported that the density of blue sheep in the Tashkurgan Nature Reserve is 2.5 individuals $/ \mathrm{km}^{2}$. According to these data, blue sheep has a relatively high density in Xinjiang, though they have just narrow belt of distribution in southern Xinjiang.

\subsection{Ibex, Capra sibirica}

Ibex was classified as a Category I state protected species, listed as endangered (EN) in the China Red Data Book, Least Concern in IUCN red list (Reading and Shank, 2008). This species inhabits in mountain ranges of central and northeastern Afghanistan, China (northwestern of Gansu, western Inner Mongolia, Xinjiang), northern India, eastern Kazakhstan, Kyrgyzstan, Tajikistan, Mongolia, northeastern Uzbekistan (western Tianshan Mountains), northern Pakistan, Russia (southern Siberia, southern Tuva, and Altay Mountains) (Reading and Shank, 2008). In Xinjiang, ibexes are spread in Altay Mountains, western mountains of Junggar Basin, Tianshan Mountains and Pamir Plateau. The nominative subspecies (C. s. sibirica) are distributed in Altay and mountains of western Junggar Basin, C. s. dementievi lives in Kunlun Mountains near their junction with Karakorum and Pamir (Wang, 1998), and C. S. hagenbecki occurs in Gobi of China-Mongolia border, and C. s. alaiana is spread in Tianshan Mountains. According to our investigations, ibexes were not found in central and eastern parts of Kunlun Mountains.

Ibex prefers rocky cliff terrain, open alpine grassland and crags on the elevation from $500 \mathrm{~m}$ to $6,700 \mathrm{~m}$ above sea level, seeking out lower slopes during winter (Fedosenko and Blank, 2001). This species have good eye-sight, keen ear and acute sense of smell and move adroitly and quickly along the steep cliff terrain. Ibexes are more active at sunrise and sunset times, and rest in cliffs during daytime. During feeding period they prefer graminoids (Artermisia, Allium) and some shrubs.
$\mathrm{Gu}(1990)$ reported that the density of ibex in Aierbin Mountains was 1.25 individuals $/ \mathrm{km}^{2}, 1.38 \pm 0.87$ individuals $/ \mathrm{km}^{2}$ in Tuolimayile, 0.37 individuals $/ \mathrm{km}^{2}$ in Taxkorgan Nature Reserve, respectively (Schaller et al., 1987). Shackleton (1997) estimated that the total number of ibexes in Tianshan was about 40,000-50,000 individuals. Ibex was rare in other regions, 4,000-5,000 individuals occurred in Beishan Mountains (northwestern Gansu), and they were maybe extinct in Daqingshan (Inner Mongolia). According to recent investigation, it is common to see ibex groups from several to dozens individuals in the inhabits. Totally, the number of ibexes is much bigger than that of argali.

\section{Discussion and suggestions}

\subsection{Genetic diversity protection of wild camel}

Distribution area of wild camels included several small isolated regions without any connection each other. This means absent corridors for gene exchange between small populations. Additionally, the density of wild camels is quite low. For example, the population of Taklimakan desert consisted of 40-60 individuals only. The long-time isolation will cause inbreeding and loss of genetic diversity obviously. So, the researches on vitality, productivity and genetic diversity among the small isolated populations need to be carried out.

\subsection{Moschus chrysogaster, Procapra przewalskii, and Saiga tatarica in Xinjiang}

Our investigation in March, 1993 found Moschus chrysogaster was distributed in Xinjiang. It was an individual in the rocky massifs of eastern Tianshan. Unfortunately, we had no time to take a photo before the Alpine musk deer disappearance. However, we are sure that it was Moschus chrysogaster according to the following reasons: (1) This species was seen by many persons in our team, and we checked immediately a picture in the handbook; (2) Only one individual was found, that is consistent with the solitary habit of this species; (3) The habitat was suitable for alpine musk deer; (4) This area was adjacent to the western edge of natural habitat of this species.

Zheng (1994) reported that the distribution area of Przewalski's gazelles includes Arjin Mountains. It was 
the first information about inhabiting of this species in Xinjiang. Przewalski's gazelles live in the transition of steppe and desert grassland (Jiang, 2004), and this description of habitats was around Qinghai Lake only. Arjin Mountains is the extremely arid environment and not so suitable for Przewalski's gazelles. Apparently, Prezewalski's gazelle is absent in Xinjiang; the information about this species distribution in Arjin Mountains should be corrected.

Saiga was distributed once in northeastern Junggar Basin and Junggar Gate before its extinction in 1960s. It was said that soldiers saw saiga and found its horn in Beita Mountains during the period of 1950s-1960s. In 1984, Xinjiang Medicine Company had collected saiga horn from the Junggar Gate. The local herdsmen from Junggar Gate said that they had seen several small groups of saiga, and each of them had 3-4 individuals. So, we supposed that it is still possible to note that some remnant groups of saiga occurred near the China-Kazakhstan border.

\subsection{Rational use of Capra sibirica}

Capra sibirica was classified as grade I state protection animals. In view of its wide distribution and presumed large population, ibex is listed as Least Concern in IUCN red list (Reading and Shank, 2008). In recent years, the ibex population in the Tianshan Mts. was estimated about 40,000-50,000 individuals (Wang, 1998). The densities in other areas are relatively low. The estimated ibex numbers in the Beishan Mountains (northern Gansu) are between 4,000 and 5,000 individuals. According to recent years' investigation, the population number of ibex is remarkably higher than that argali sheep. We suggest the forestry department of Xinjiang to take measures to assure the rational use of Capra sibirica.

\subsection{Enhancing natural habitat protection and enlarging monitoring projects for Pantholops hodgsoni.}

Pantholops hodgsoni has been classified as grade I state protection animals in China, distributes widely in Qinghai-Tibet Plateau and can be found in Tibet, Qinghai, Sichuan, Gansu and Xinjiang. According to

\section{References}

Bannikov A G. 1958. Geography distribution and biology of wild horse and wild camel in Mongolia (Equus przewalskii and Camelus bac- the investigations the population number in Karakorum-Kunlun Mountains was about 90,000 individuals and may be more than 100,000 all over the Qinghai-Tibet Plateau (Feng, 1992). Schaller (1998) estimated that antelopes' population was $<75,000$ individuals. However, during recent years, the population of Tibetan antelopes grows up quickly, because of effective protection measures. At present, some Chinese scientists believed that total number of Pantholops hodgsoni in China is 150,000 individuals (Mallon, 2008).

In spite of the good conservation status of Tibetan antelope at present, the future of this species still stayed uncertain because of building new railway line across the Tibet and other human activities for economic development in this region. Therefore, the forestry department should enhance efforts for protection natural habitat of Tibetan antelopes, and also enlarge monitoring and researching projects of this species. If possible, we suggest that the forestry department of Xinjiang assess the possibility on captive breeding of Tibetan antelope, to make rational use of their skin and fur. We believe that the captive breeding can weaken the poaching pressure.

\subsection{Captive breeding of Cervus elaphus}

Xinjiang has a long history for the red deer breeding. The technology and process of the products are quite proficiency after over 50 years' development. Now there are over 2,000 captive breed farms with nearly 50,000 individuals of red deer in Xinjiang. The local governments should lessen monitoring control after work of breeding centers for Cervus elaphus and enhance the development of market mechanisms and regulation of this business. We suppose that this management reform will lead to the considerable boost of this industry.

\section{Acknowledgements}

We are grateful to Chinese Academy of Sciences Visiting Professorships for Senior International Scientists (2009Z2-5) and Sino-Italian Cooperation Project (0866031) for financing this research.

trianus). Mammalia, 22(1): 162-156.

Bannikov A G, Lobanov N W. 1980. Przewalski horse. Priroda, 3: 
$100-105$.

Chu H J, Jiang Z, Ge Y, et al. 2009. Population densities and number of khulan and goitred gazelle in Mt. Kalamaili Ungulate Nature Reserve. Biodiversity Science, 17: 414-422.

Fedosenko A K, Blank D A. 2001. Capra sibirica. Mammalian Species, 675: 1-13.

Fedosenko A K, Blank D A. 2005. Ovis ammon. Mammalian Species, 773: 1-15.

Feng Z J. 1992. Resource Status of Mammals in Qinghai-Tibet Plateau. Collectanea of First Symposium of Qinghai-Tibet Plateau Seminar, Beijing: Science Press, 187-195.

Gao X Y. 1985. The wild horse and wild camel of China passed checkup at the Urumqi. Acta Theriologica Sinica, 5 (4): 290.

Gao X Y, Gu J H. 1989. The distribution and status of Equidae in China. Acta Theriologica Sinica, 9(4): 269-274.

Gao X Y, Xu K F, Yao J, et al. 1996. The population structure of Goited Gazelle in Xinjiang. Acta Theriologica Sinica, 16(1):14-18.

Gao X Y, Qiao R L, Xiong Y F, et al. 1997. The investigation report of red deer resource in Changji Prefecture. Arid Zone Research, 14(Suppl.): 5-10.

Gao X Y, Yao J. 1997. Argali sheep in Estern Tianshan Mt, Xinjiang. Chinese Wildlife, (18): 38-40.

Gao X Y, Yang W K, Qiao J F, et al. 2001. Status and distribution of large mammals in Xinjiang, People's Republic of China. Pakistan Congress of Zoology, 21: 305-322.

Gao X Y. 2003. A Checklist on the Classification and Distribution of Vertebrate Species and Subspecies in Xinjiang. Urumqi: Xinjiang Science and Technology Publishing House, 204-211.

Gao X Y, Yao J. 2006. Study on the geography distribution and population of Gazella subgutturosa in the Hami Basin, Xinjiang in early winter. Arid Land Geography, 29 (2): 213-218.

Gentry A, Clutton-Brock J, Groves C P. 2004. The naming of wild animal species and their domestic derivatives. Journal of Archaeological Science, 31: 645-651.

Gu J H. 1987. The ungulate in Eastern Kunlun Mt. and Arjin Mt., Xinjiang. Arid Zone Research, 4(3): 56-68.

Gu J H, Gao X Y, Zhou J D. 1991. Status and Distribution of Wild Two-humped Camel in Xinjiang. Studies on the Animal in Xinjiang. Beijing: Sciences Press, 1-9.

Gu Z Q. 1990. Preliminary report of Ibex on the population in Aierbin Mt. Bazhou Science and Technology, (3): 6-10.

Hare J. 2010 Camelus ferus. IUCN Red List of Threatened Species. [2010-05-30]. http://www.iucnredlist.org.

Harris R B. 2010. Pseudois nayaur. IUCN Red List of Threatened Species. [2010-06-26]. http://www.iucnredlist.org.

Harris R B, Leslie D. 2010. Bos mutus. IUCN Red List of Threatened Species. [2010-05-30]. http://www.iucnredlist.org.
Jiang Z G. 2004. Przewalski's Gazelle. Beijing: China Forestry Publishing House, 66-71.

Jiang Z, Wang S. 2001. China. In: Mallon D P, Kingswood S C. Antelopes, Global Survey and Regional Action Plans. Part 4: North Africa, the Middle East, and Asia. Switzerland: Global Survey and Regional Action Plans, IUCN, Gland. 168-177.

Lovari S, Herrero J, Conroy J, et al. 2009. Cervus elaphus. IUCN Red List of Threatened Species. [2009-12-01]. http://www.iucnredlist.org.

Mallon D P. Saiga tatarica. 2010. IUCN Red List of Threatened Species. [2010-05-30]. http://www.iucnredlist.org.

Northwest Institute of Plateau Biology, Chinese Academy of Sciences. 1989. Economic Fauna in Qinghai. Xining: Qinghai people's Publishing House, 629-658.

Reading R, Shank C. 2009. Capra sibirica. 2008. IUCN Red List of Threatened Species. [2009-12-01]. http://www.iucnredlist. org.

Schaller G B, Li H, Tailipu Ren J, et al. 1987. Status of large mammals in the Taxkorgan Reserve, Xinjiang, China. Biological. Conservation, 42: 53-71.

Schaller G B. 1998. Wildlife of the Tibetan steppe. Chicago: University of Chicago Press, 41-79, 163-177.

Shackleton D M. 1997. Wild Sheep and Goats and their Relatives-Status Survey and Conservation Action Plan for Caprinae. Switzerland: IUCN/SSC Caprinae Specialist Group. 148-171.

Shah N, St. Louis A, Huibin Z, et al. 2010. Equus kiang. IUCN Red List of Threatened Species. [2010-05-29]. http://www.iucnr- edlist.org.

Sokolov. 1959. The Fauna of USSR, Mammals. Vol. 1, part 3. Moscow: The Academy of the USSR, 26-63.

Wang X T. 1991. Vertebrate Fauna of Gansu. Lanzhou: Gansu Science and Technology Publishing House, 1186-1232.

Wang S. 1998. China Red Data Book of Endangered Animals: Mammalia. Beijing: Science Press.

Wang Y X. 2003. A Complete Checklist of Mammal Species and Subspecies in China, A Taxonomic and Geographic Reference. Beijing: China Forestry Publishing House, 113-132.

Wang Y, Harris R B. 2010. Moschus chrysogaster. IUCN Red List of Threatened Species. [2010-05-30]. http://www.iucnredli- st.org.

Xu K F, Ren Z G, Gao X Y. 1997. The resource and status of Mongolian wild Ass and Goitred Gazelle in Kalamaili Mt. Reserve. Arid Zone Research, 17(Suppl.): 17-22.

Yu Y Q, Hu Y W, Zhou F Q. 1996. Taxonomy distribution and status of Red Deer in Yili, Xinjiang. Journal of Northwest University, 26 (Suppl.): 831-835.

Zhao J N, Gao X Y, Zhou Y H. 1991. Distribution of Argali in China. Journal of Xinjiang Agriculture University, 14(3): 64-67.

Zheng S W. 1994. Rare and Endangered Animals in Northwestern China. Beijing: Chinese Forestry Press, 112-186. 